\title{
Large-scale Renewable Energy Project Barriers: Environmental Impact Assessment Streamlining Efforts in Japan and the EU
}

\author{
By Kim Schumacher,Ph.D. (kim.schumacher@smithschool.ox.ac.uk) \\ https://doi.org/10.1016/j.eiar.2017.05.001
}

(C)2017. This manuscript version is made available under the CC-BY-NC-ND 4.0 license http://creativecommons.org/licenses/by-nc-nd/4.0/

\begin{abstract}
Environmental Impact Assessment (EIA) procedures have been identified as a major barrier to renewable energy (RE) development with regards to large-scale projects (LS-RE). However EIA laws have also been neglected by many decision-makers who have been underestimating its impact on RE development and the stifling potential they possess. As a consequence, apart from acknowledging the shortcomings of the systems currently in place, few governments momentarily have concrete plans to reform their EIA laws. By looking at recent EIA streamlining efforts in two industrialized regions that underwent major transformations in their energy sectors, this paper attempts to assess how such reform efforts can act as a means to support the balancing of environmental protection and climate change mitigation with socio-economic challenges. Thereby this paper fills this intellectual void by identifying the strengths and weaknesses of the Japanese EIA law by contrasting it with the recently revised EIA Directive of the European Union (EU). This enables the identification of the regulatory provisions that impact RE development the most and the determination of how structured EIA law reforms would affect domestic RE project development. The main focus lies on the evaluation of regulatory streamlining efforts in the Japanese and EU contexts through the application of a mixed-methods approach, consisting of in-depth literary and legal reviews, followed by a comparative analysis and a series of semi-structured interviews. Highlighting several legal inconsistencies in combination with the views of EIA professionals, academics and law- and policymakers, allowed for a more comprehensive assessment of what streamlining elements of the reformed EU EIA Directive and the proposed Japanese EIA framework modifications could either promote or stifle further RE deployment.
\end{abstract}

Keywords: Environmental Impact Assessment Law, Streamlining, Japan, European Union, Renewable Energy

\section{Introduction}

The announcement of the restart of the Sendai I nuclear reactor near the city of Kagoshima by the Kyushu Electric Power Company (Kyuden) marks a fundamental reversal in Japan's postFukushima energy strategy (Johnston and Yoshida, 2015). This represents the first restart since the 2011 Fukushima Daiichi nuclear disaster, which led to the complete shutdown of Japan's entire nuclear reactor park. This also left the country in a situation where they had to rely increasingly on conventional thermal power generation in order to compensate the loss of generation capacities, since almost one third of its domestic electricity demand was supplied by nuclear power just before the Fukushima incident (Johnston and Yoshida, 2015).

The current government plans to restart most of the currently offline nuclear power plants and increase the share of nuclear power to $20-22 \%$ by 2030 (JFS, 2016a). This evolution stands in stark contrast to the views held by the general population, among which still a large majority opposes nuclear power (Johnston and Yoshida, 2015). According to the government, nuclear 
power, as a domestic, base-load source is indispensable if Japan wants to reduce reliance on energy imports, maintain output and grid stability besides keeping electricity rates low while simultaneously reducing GHG emissions.

Increased reliance on energy imports in a geo-politically fragile world energy market environment as well as volatile commodity prices and rising greenhouse gas (GHG) emissions, in combination with strong adversity towards nuclear power among the general population, made renewable energy (RE) power generation seem like a readily available, socially acceptable domestic solution to the country's energy woes in the immediate aftermath of the 2011 disaster (Haarscher et al., 2014).

In June 2012, with the introduction of a general Feed-in Tariff (FiT) that had some of highest rates for RE producers in the world, the Japanese government wanted to provide the necessary support and financial incentive for RE power generation projects aiming to increase the at that time negligible share of RE in the general energy mix (JFS, 2013).

However, despite significant subsequent growth in RE power generation capacities after the introduction of the general FiT, the overall deployment figures between the various RE sources supported under the FiT scheme diverged largely from one another. The overwhelming majority of eligible investments have been focusing mainly on solar PV, whereas other forms, most notably wind and geothermal, constitute only small fractions of the FiT project approval applications (Kotsubo and Takeuchi, 2013). In stark contrast to the large energy and development potential of wind and geothermal resources in Japan, these forms of RE power generation continue to represent only very small percentages of overall electricity production (Schumacher, 2015).

The Japanese government announced in April 2015 that Japan wants to increase the share of renewables in the total electricity power generation from currently 13\% (including large hydroelectricity) to $22-24 \%$ in 2030 (Urakami, 2015). Taking into consideration the recent progressive levelized lowering of FiT rates, coupled with the fact that all major large hydroelectricity sites have already been developed, the question arises how Japan will be able to achieve the desired energy mix (METI, 2015). Moreover in June 2015, in anticipation and preparation to the United Nations (UN) COP21 climate change summit held in Paris in December 2015, the Japanese government also approved a plan to reduce GHG emissions by $26 \%$ by 2030 , with 2013 serving as the baseline year (JFS, 2016a).

Given the fact that its national GHG emissions saw a steep increase after the Fukushima disaster, as a result of Japan expanding its thermal power capacities in order to offset the complete shutdown of all its nuclear power facilities, this emission reduction target appears difficult to attain, even with the less ambitious 2013 baseline year and the assumption of nuclear power approaching pre-Fukushima levels (JT, 2015). In light of the aforementioned goals of a $22-24 \%$ renewables share of TPES and a $26 \%$ GHG emissions cut by 2030 , largescale wind power and geothermal power developments could contribute significant shares to Japan's energy mix, but due to several administrative barriers emanating from the country's environmental laws that appear to partially neutralize the benefits of the FiT, investments and project development have been stagnating in comparison to solar PV, which is largely exempt from these environmental assessment regulations (Azechi et al., 2012; Shibata et al., 2015; Watanabe and Stapczynski, 2016).

Being aware of some of the administrative constraints that have been adversely affecting the environmental approval and permitting stages, the Japanese government has been attempting to deregulate and streamline the stringent national environmental laws, most notably the environmental impact assessment (EIA) law, by modifying and adapting some of the most prohibitive provisions within the various legal frameworks (MOEJ, 2012b; MOEJ, 2013). The majority of these measures proved to be of mostly palliative nature, as their impact has 
remained relatively limited, and growth rates for wind power and geothermal have been continuing to be comparatively low or at times even decreasing (Azechi et al., 2012; Nishikizawa et al., 2013; Shibata et al., 2015).

In absence of comprehensive, integrated environmental law reform efforts and looking at a OECD member region with similar economic weight and structured RE issues for entire territory, this paper aims at comparing the Japanese measures in juxtaposition to the EIA legal framework of the European Union (EU), which has recently been reformed as well, in order to determine what elements of the EU EIA law could be implemented into the Japanese EIA law in order to strengthen and streamline the environmental approval process as well as reduce the administrative barriers to LS-RE development. Examples and cases from different EU member states (Germany, United Kingdom, Ireland, Belgium and Bulgaria) will be used to illustrate some of the strengths and weaknesses of the EIA process in Europe.

This paper focuses for the most part on the administrative barriers for large-scale geothermal power in Japan and large-scale onshore wind power for Japan and the EU, as these represent the RE sources with the most similar energy potential rates and administrative obstacles (IEA, 2015). Finally, applying comparative analysis expands the scope of the discussion in what ways EIA and environmental laws in general can act as barriers to RE development beyond national or transatlantic considerations.

\section{Methodology}

In order to assess the strengths and weaknesses of each EIA framework, a levelized mixedmethodology approach was applied. The first step consisted of in-depth literary and legal reviews of the current rules in place, followed by the identification of the regulatory elements that acted as development barriers to RE projects. The literary review was concluded by outlining the planned or already enacted reform and streamlining measures in each jurisdiction. The next step consisted of the conception of evaluation criteria presented in Table 1 that allowed for an objective assessment of the fundamental requirements set by EIA procedural steps for developers. These criteria were then integrated into a comparative qualitative data analysis that highlights the likely impact of each procedural component.

Table 1

Evaluation Criteria of the Japanese and EU EIA Frameworks (after Galás et al., 2015)

\begin{tabular}{|c|c|c|}
\hline Issues & Analysis and Evaluation & Evaluation Criteria \\
\hline A) In the procedural framework & Legal frameworks and reform proposals & $\begin{array}{ll}- & \text { Number of procedural stages } \\
\text { - } & \text { Number of procedural } \\
\text { - } & \text { requirements per stage } \\
\text { - } & \text { Public input possibilities } \\
\text { - } & \text { Administrative facilitation } \\
\text { - } & \text { Overall Procedural Duration } \\
\text { Overall Cost }\end{array}$ \\
\hline B) In the practical application & $\begin{array}{l}\text { Expert opinions and semi-structured } \\
\text { interviews }\end{array}$ & $\begin{array}{ll}\text { - } & \text { Consideration of industry } \\
\text { concerns in reform efforts } \\
\text { - } & \text { Public input variations } \\
\text { - } & \text { Political willingness to reform } \\
\text { - } & \text { Perceived strong and weak points } \\
\end{array}$ \\
\hline
\end{tabular}

The final step consisted of a conceptualized research framework integrating the opinions obtained through semi-structured expert interviews, incorporating established techniques described by Bryman (2008), conducted with individuals both in Japan and the EU between 
October 2013 and January 2016, and covering various sectors (academia, project development, energy sector, government agency, lawmaker), into the respective conceptualized EIA policy frameworks. The questions addressed issues of EIA framework efficiency, procedural shortcomings and streamlining effort evaluation. The interviewees listed in Table 2 are allocated codes for the Japanese (JP1- JP17) and EU experts (EU1-EU4) to guarantee their anonymity (Bryman, 2008). To offset the small EU sample size, I also cross-checked the EU responses with an official EU questionnaire in which national EIA legislators and administrators were asked to respond to the proposed Directive 2014/52/EU alterations (Clement, 2014; EUFJE, 2014; Philipp and Sangenstedt, 2014; Ciobanu-Dordea, 2014).

Table 2

Semi-structured JP and EU Expert Interviews

\begin{tabular}{ll}
\hline EIA Experts classified by sector* & \\
\hline Sector & Number of interviewees \\
\hline Academia & 6 (JP1-5, EU1) \\
Project Development & 2 (JP6-7) \\
Energy Sector & 2 (JP8-9) \\
Government Agency & $6(\mathrm{JP} 10-14$, EU2) \\
Legislator & $2(\mathrm{EU} 3-4)$ \\
Think Tank and Consulting & $3(\mathrm{JP} 15-17)$ \\
\hline Total & 21 \\
\hline
\end{tabular}

\section{EIA Frameworks: Japanese Legal Context}

\subsection{National Environmental Legal Framework}

In Japan, the environmental approval process illustrated in Fig. 3 for wind power and geothermal power plants is currently enshrined mainly in two different pieces of legislation, as shown in Fig. 1. the first being the Basic Environment Law 1993 (hereafter BEL) and the Environmental Impact Assessment Law 1997 (hereafter EIAL) (MOEJ, 2012a).

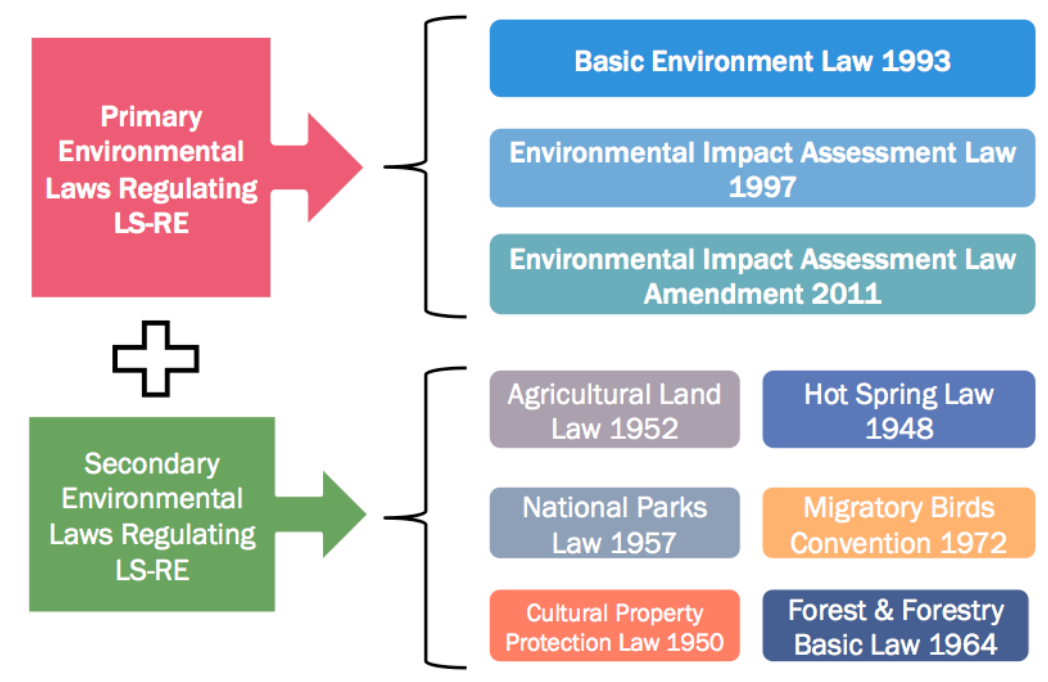

Fig. 1. Major Japanese Environmental Laws affecting LS-RE (Source: MOEJ)

The BEL, which originates from the 1967 "Basic Law for Environmental Pollution Control" and the 1972 "Nature Conservation Law" and combined the provisions therein into one single 
framework, regulates all major general environmental areas, such as protection of biodiversity and wildlife species, air pollution, water pollution, soil contamination, noise pollution, vibrations, offensive odor or ground subsidence (Nagano, 2012; MOEJ, 2016). The legal details of these areas listed by the BEL are then regulated in specific laws pertaining to each policy area (Schumacher, 2015).

The EIAL then creates an approval procedure for development projects that are likely to have a significant impact on the environment in order to conform these activities with the most common sustainability principles and minimum environmental protection standards. The EIA procedure is started by launching an application with the Ministry of Environment (MOEJ) and will include input by the public, local authorities (prefectures and municipalities), the project proponents and the national government, represented by the MOEJ and, in the case of power plants, by the Ministry of Economy, Trade and Industry (METI). Before final approval is given, MOEJ has to issue a final consultative and non-binding opinion. Afterwards METI will issue the final decision on whether to approve a development license or not (MOEJ, 2012a). Furthermore, local governments such as prefectures and municipalities can create their own supplementary local EIA ordinances for all aspects not explicitly covered by the national EIAL, thus creating a large catalogue of differing EIA rules (MOEJ, 2012a; METI, 2016b).

In 2011, the EIAL was amended, adding several procedural steps at the beginning and at the end of the EIA process. By integrating PEIC and IMR, which entered into full force in 2013, the government wanted to create additional possibilities for public input and overall planning consideration, in line with more broad SEA principles, without having to create a specific entirely separate SEA law (MOEJ, 2012a).

The large majority of RE power plant projects are subject to the EIAL and the environmental approval procedures stipulated therein. Solar PV is currently a notable exception as projects falling within this category, irrespective of size and production capacity, are not subject to the EIAL (Watanabe and Stapczynski, 2016). Wind power was originally exempt as well, however with the 2011 EIAL amendment it was added to list of projects subject to an EIA, primarily out of environmental concerns, mostly linked to low frequency sounds, noise and the elevated risk of bird collisions (MOEJ, 2012a).

Fig. 2. Illustrates that EIAs are always mandatory for wind power and geothermal power plants exceeding an electricity production capacity of $10 \mathrm{MW}$. Power plants with a production output capacity situated between $7.5 \mathrm{MW}-10 \mathrm{MW}$ are subject to a screening procedure in order to determine whether or not they fall within the scope of the EIAL (MOEJ, 2012a).

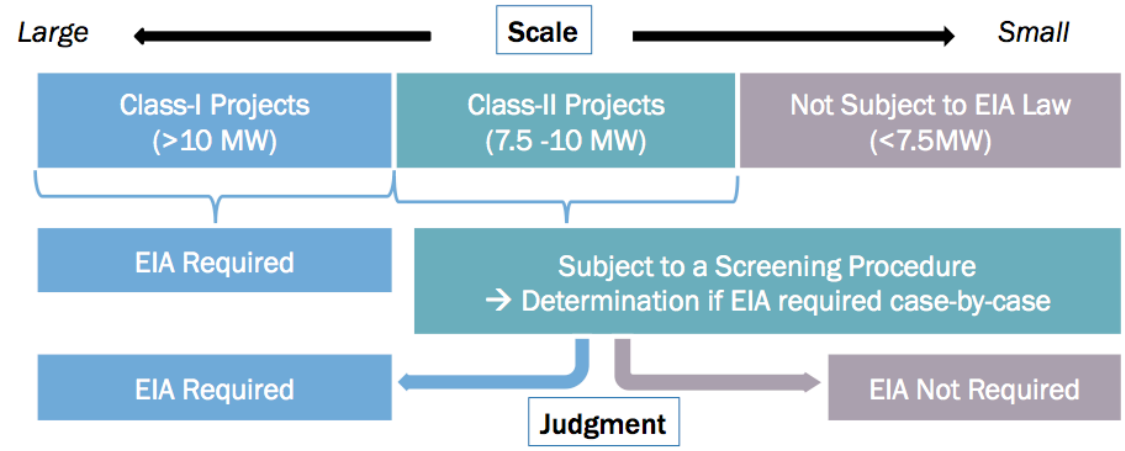

Fig. 2. Classification categories for National EIA Screening (Source: MOEJ)

Besides these two main pieces of environmental legislation, several other laws have to be consulted as well during the various project development stages and the subsequent approval process, such as the "Hot Spring Law 1948" and "Natural Parks Law 1957", the "Migratory 
Birds Convention 1972", the "Cultural Property Protection Law 1950" or the "Agricultural Land Law 1952" . The approval procedures outlined within these laws are sometimes concurrent or separate from the main EIA process and require separate approval from different authorities (Schumacher, 2015; MOEJ, 2012a; JFS, 2014a; JFS, 2014d; MOEJ, 2015).

\subsection{EIA-related Barriers to Large-Scale RE Development}

The EIAL was introduced with the intent of factoring in potential risk to the environment by future project developments such as the construction of power plants, roads, railways or dams. Despite this being considered an important step in raising environmental awareness and protecting natural resources, some of the structural requirements and procedural steps of the EIAL have been considered to bear the potential of acting as barriers to LS- RE development (Uesako et al, 2013; Ito, 2014; METI, 2016a).

Given the fact that large-scale wind power and geothermal plants require EIAs at all times, some of the aforementioned additional procedural alterations in the permitting process, notably PEIC and IMR, can prolong the overall length of the latter to an extent where the basic economic viability of the whole project might be put in peril. Numerous Japanese wind and geothermal power industry representatives cited the lengthy, cumbersome and costly EIA process as one of the main reasons in cases where projects were abandoned before the issuance of the final ministerial development license or permit decision (Azechi et al., 2012; Nishikizawa et al., 2013; JFS, 2014b). Average duration currently stands at three, with some large-scale wind farms or geothermal power stations having gone or going through EIA longer than five years (Nagano, 2012; Azechi et al. 2012; METI, 2016a).
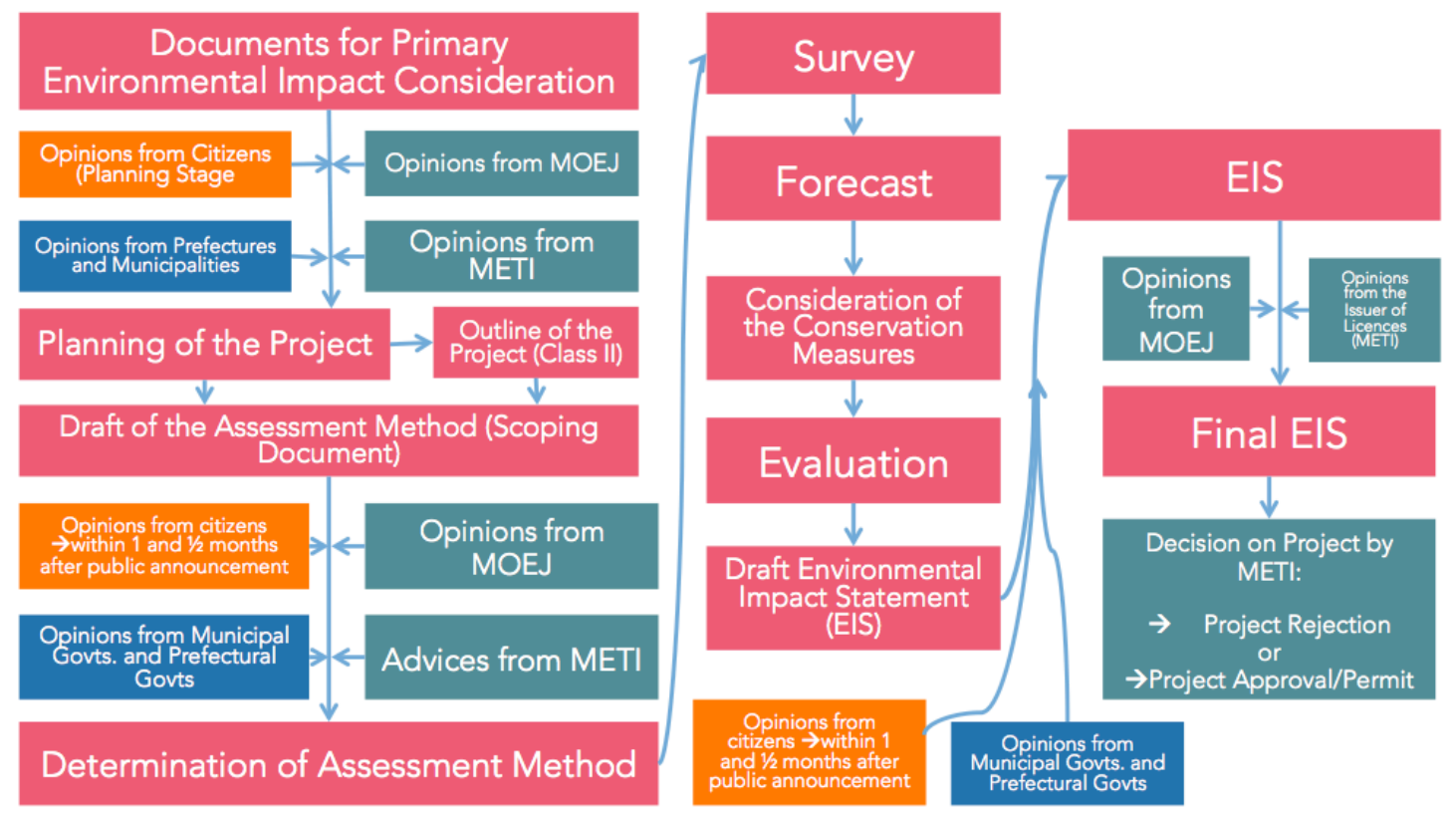

Fig. 3. Basic EIA procedural steps for LS-RE projects (Source: MOEJ)

The major points, with regards to the flaws of the EIAL that are voiced by developers are the numerous procedural steps prescribed by the EIAL (Uesako et al, 2013; Ito, 2014; METI, 2016a). As can be seen in Fig. 3., the law contains a multitude of occasions for stakeholders and authorities to participate throughout the whole process, starting with the PEIC, then at both the screening and scoping stages, next after the first draft environmental impact 
statement (EIS), penultimately before the final EIS and eventually at the impact mitigation report (IMR) post-monitoring stage as well (MOEJ, 2012a). This produces a large number of agencies and stakeholders participating in the process, whose opinions and views all have to be protocoled, acknowledged and duly considered in the project proponents' EIS (MOEJ, 2012a; METI; 2016a; Uesako, 2013). This can create a complex set of sometimes opposing interests that bear significant conflict potential, which again can prolong the EIA process duration exponentially.

Another administrative barrier is the large number of laws that developers of onshore LS-RE projects have to consider as well, including the aforementioned Hot Spring Law, the Migratory Bird Law, the Natural Park Law or the Agricultural Land Law. Hot spring owners for example can completely and almost indefinitely block geothermal projects on the basis of concerns that the project would deplete the hot water reservoir (JFS, 2014a). In addition, environmental non-profit organizations (NPOs) are able to stall wind power projects due to the stringent bird protection laws as well (Demizu, 2016). Furthermore the government has been limiting and heavily regulating geothermal and wind power development in natural parks, which are subdivided into special protection zones where any type of development is strictly forbidden. Then there are class 1-3 special zones, where development is only allowed with special permits and under very specific conditions (Katori, 2015). Finally, the government regulates the use of agricultural land and has limited almost the entirety of nonagricultural activities, citing the importance of prime agricultural land as the main reason in natural resource-scare and mountainous Japan (JFS, 2014d).

The absence of an integrated permitting process forces developers to seek separate authorizations from different government bodies, which in combination with these rigid landuse provisions and the additional requirements introduced by the 2011 EIA amendment have created a situation that in numerous instances appears to be either too onerous or uncertain for many developers to continue, therefore many choose either to abandon LS-RE projects almost altogether or opt in favor of investing in small-scale installations or solar PV, not subject to the EIAL (Azechi et al., 2012; Nishikizawa et al., 2013).

\subsection{Environmental Approval Procedural Reform Efforts}

To address these criticisms, the Japanese government and its ministries recently started several small-scale reforms with the intent of facilitating the development of large-scale onshore wind farms and geothermal power stations in order to achieve more diversified and broad RE generation capacity growth besides the one that the solar PV sector has been experiencing since the introduction of the FiT in 2012.

One of the approaches that has been taken is among others a EIAL reform draft that includes plans by MOEJ and METI to cut the average duration of the EIA process from momentarily three years on average to eighteen months (Uesako, 2013; METI, 2016a). As outlined in Fig.4., this will be achieved through various incentives and implementing a number of streamlining measures, mainly by applying a more integrated simultaneous planning process in which all of the relevant EIAL as well as secondary law procedural steps (e.g. Hot Spring Law, Natural Park Law, etc.) will be launched and performed at the same time. Moreover, further streamlining will be achieved by relying more heavily on previous survey and prediction data and conducting the main central government EIA review in coordination with the local government review procedures as to avoid double examination of nearly identical review elements (Uesako, 2013; METI, 2016a). 


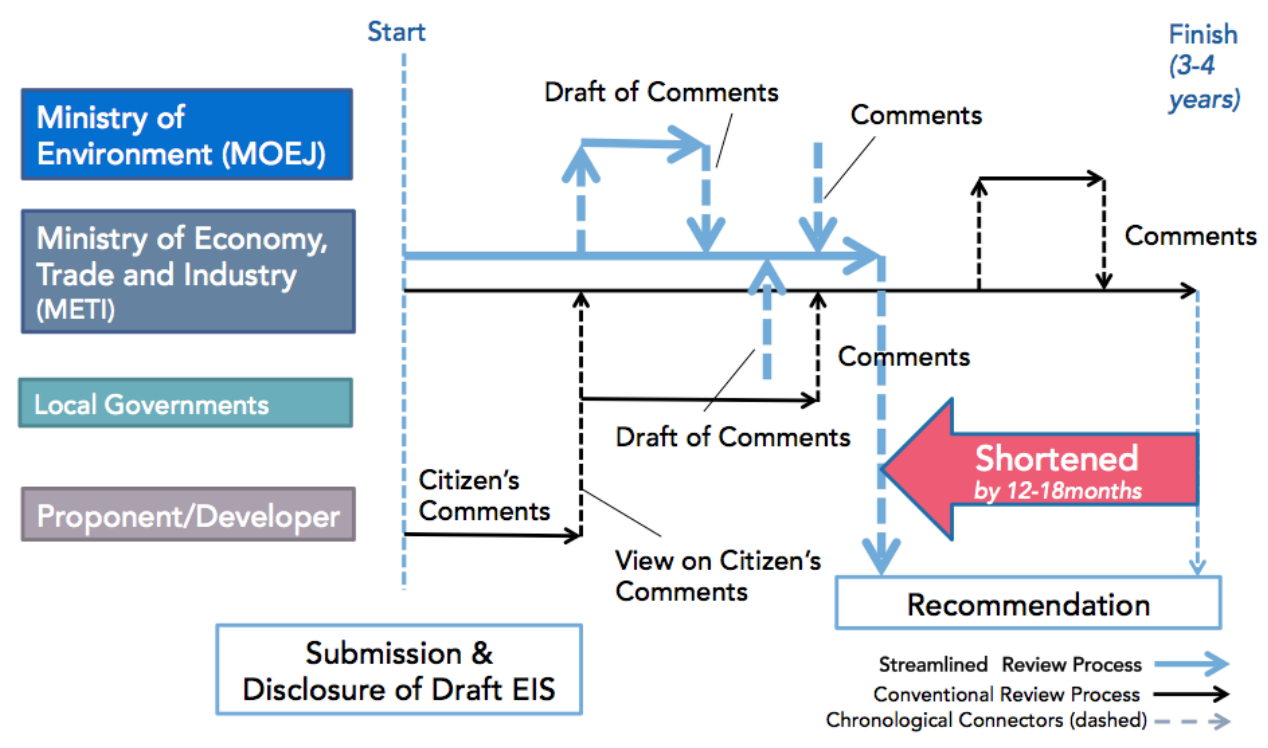

Fig. 4. Japanese Proposal for the Shortening of the EIA Review Process (Uesako, 2013)

In an attempt to facilitate the administrative burden prior to the EIS stage, the MOEJ is also creating a database that will collect survey data, conducted either by MOEJ or private developers, and subsequently render it publicly available in order to reduce cost and administrative backtracking for multiple identical or similar surveys by future project proponents (METI, 2016a). Another idea that is being considered is a system of designated zones, in which construction of wind power plants would be allowed at all times, whereas in areas outside of these zones, construction would be very limited. This proposal is inspired by the German system of government agencies or ministries designating pre-determined and preapproved zones that benefit from streamlined administrative procedures in terms of RE development (METI, 2016b) (TU Berlin, 2011). In these zones, all of the relevant studies and required environmental surveys would already have been conducted by the government prior to the start of the project development, thus enabling interested developers to bypass any EIArelated administrative procedural steps and advance to the construction phase in case their project bid is accepted (METI, 2016b).

A measure already in the testing stage is an incentive program administered by METI that will reimburse $50 \%$ of the cost for a pre-PEIC survey whose date will subsequently be made available publicly to reduce overall EIA costs and duration (METI, 2016a). The MOEJ and METI also co-published a proposal that would reduce the overall assessment duration, as preEIA consultation and data collection procedures can now be completed parallel to the main EIA procedural steps to reduce duration and costs for developers (METI, 2016a).

Regarding the secondary laws, there have been some reform attempts as well, mainly in the form of expanding the land-use scope of the respective legal frameworks. The National Park Law formerly prohibited any development within class 1-3 special zones, yet over the course of two amendments, the government progressively permitted geothermal developments, with more or less strict limitations. Operation of geothermal power plants is currently permitted in the aforementioned special zones to differing degrees and on a case-by-case basis, whereas exploration or operation continues to remain restricted in Special Protection Zones, the highest certification for national parks (Katori, 2015).

Moreover, as previously briefly outlined, any RE developments on agricultural land, the latter being considered of high national value as well as substantial public interest in a mainly resource-scarce and mountainous country like Japan, were previously entirely forbidden. However, recent amendments enacted by the Ministry of Agriculture, Forest and Fisheries 
(MAFF) rendered RE installations such as wind farms possible, albeit only under certain conditions and on a case-by-case basis (JFS, 2014d).

After having outlined some of the procedural aspects of Japan's the environmental legal frameworks and how they might impact or potentially risk stifling RE development, we will look at the recently amended environmental assessment rules in the EU to analyze their weaknesses and strengths, in order to contextualize and evaluate their potential impact on LSRE project development.

\section{EIA Frameworks: EU Legal Context}

\subsection{National Environmental Legal Framework}

EIA law in the EU first got legally established in the Commission Directive 85/337/EEC in 1985, regulating the environmental approval process for public and private projects complying with the statutory assessment criteria defined in the directive such as project type, size or likely environmental impact (EC, 2009). Over the years, this directive got amended on three occasions: Directive 97/11/EC integrated the "UN ECE Espoo Convention on EIA in a Transboundary Context"; Directive 2003/35/EC aligned the main EIA Directive with the provisions on public participation contained in the "Aarhus Convention on Public Participation in Decision-making and Access to Justice in Environmental Matters"; and finally Directive 2009/31/EC amended the Annex I and II lists that contain the types of projects subject to the EIA Directive, extending the latter to include projects related to transport and carbon capture and storage (CCS). These three amendments were then codified into one single text by Directive 2011/92/EU (EC, 2011).

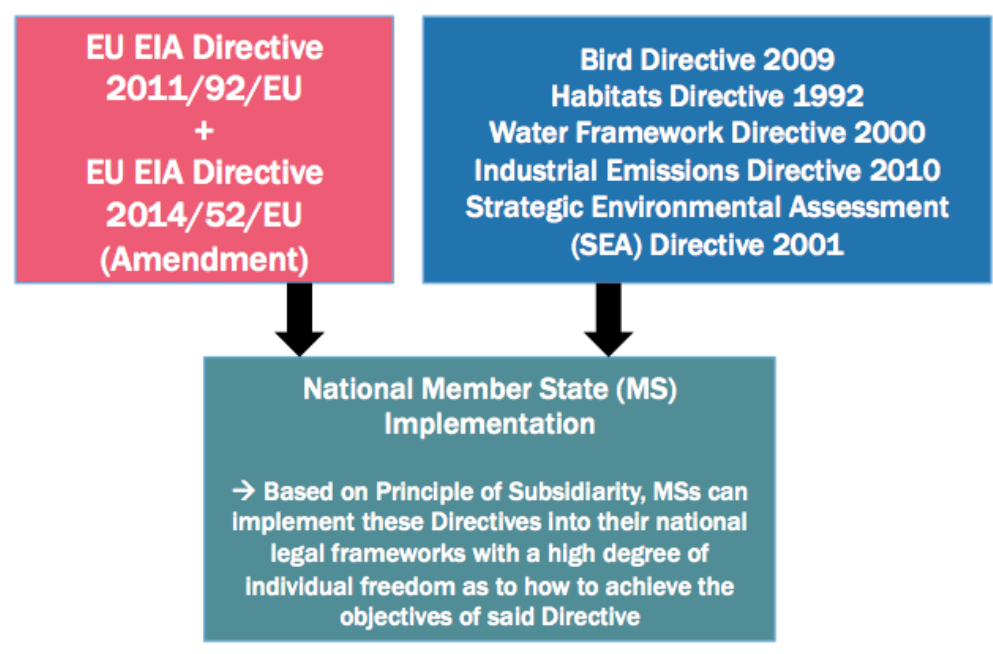

Fig. 5. EU Environmental Directives affecting LS-RE (Source: EC)

Directives apply the EU principle of subsidiarity, presented in Fig.11., which specifies that the member states are in charge of implementing the directions and guidelines contained therein into their national legal frameworks within a prescribed time-frame. Member states do possess more or less considerable leeway as to how they want achieve the minimum policy goals set out by a directive (Van Zeben, 2014).

In 2014, the EU revised the 2011 Directive with the amended Directive 2014/52/EU (hereafter the Directive), which was the result of a five-year consultation process between 
most major EU institutions (Commission, Parliament and Council), the public, environmental organizations and industry stakeholders (EC, 2012). Its implementation pursued the goal of simplifying the whole EIA process, implementing recent European jurisprudence, aiming at increasing predictability with mandatory time-frames for the national authorities responsible of the EIA review steps, creating more opportunities for public participation and achieving more overall transparency in the diffusion or dissemination of information with regards to the screening or final development consent decisions.

Fig. 6. shows that Annex I projects are always subject to an EIA, however the only LS-RE projects currently in this category are large hydroelectricity projects. Annex II of the Directive lists the projects that are not necessarily subject to EIAs, and includes wind power, geothermal power and larges-scale solar PV projects. These projects will be subject to a screening procedure, which can prolong the overall EIA duration and uncertainty for developers considerably (Directive 2014/52/EU). The Directive recommends that competent authorities should take screening decisions within 90 days, however this time-frame is nonbinding. In addition the Directive prescribes a mandatory minimum public consultation period of 30 days to address concerns over a lack of accountability and public consideration in the previous versions of the Directive.

Annex III of the Directive provides a catalogue of selection criteria for projects that fall within the scope of the Annex II screening procedure. Things that the national screening authorities need to consider are the characteristics (e.g. size, cumulation, natural resource use, etc.), the location and potential impact of the project in order determine if said project is either subject to or exempt from the EIA requirement (Directive 2014/52/EU).

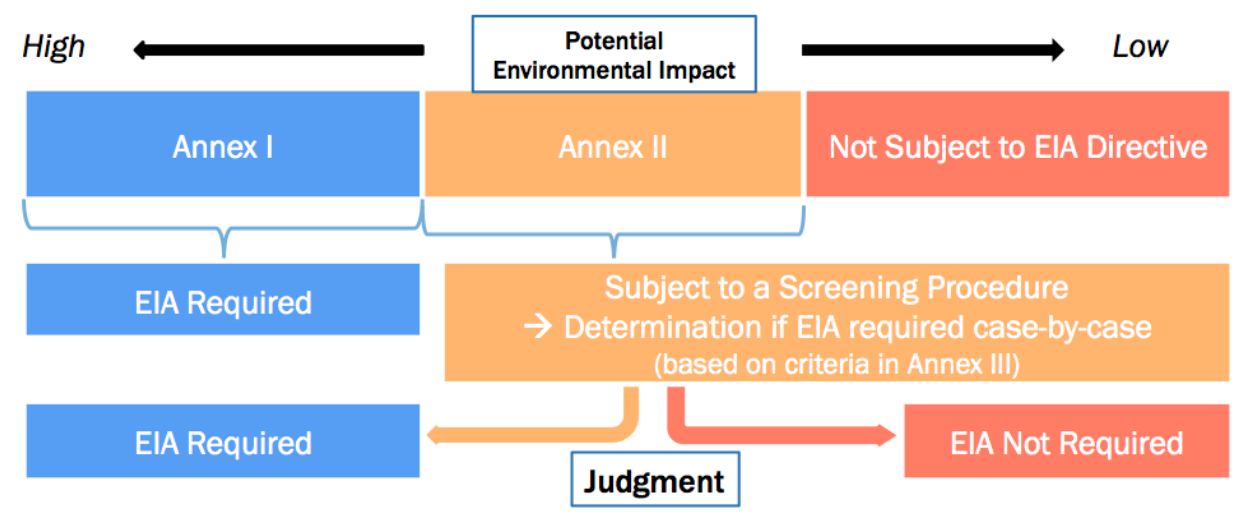

Fig. 6. Classification categories for EIA Screening (Source: adapted from 2014/52/EU)

National member states can also fix their own thresholds or criteria as to when they require an EIA, in Germany for example the German EIA act makes EIA mandatory for wind farms composed of at least 20 wind turbines exceeding 50 meters in height. Wind farms composed of 3 to 19 wind turbines exceeding 50 meter in height are subject to an EIA screening procedure (Geißler et al., 2013). In the UK, large-scale onshore wind power projects exceeding a production output of $50 \mathrm{MW}$ or above are always subject to an obligatory EIA, whereas wind power installations composed of more than five turbines or exceeding a production output of $5 \mathrm{MW}$ will be subject to an EIA screening procedure (Jones et al., 2011).

Despite the relatively high degree of flexibility offered by the Directive to the individual member states to adapt and implement the provisions set forth in the Directive into their EIA legal frameworks, the new amendment is also met with criticism from many stakeholders, among them member state officials, industry groups, politicians and environmentalists. 


\subsection{EIA-related Barriers to LS-RE Development}

Critics of the Directive mostly voice their dissatisfaction towards the fact that albeit the Directive is an improvement in certain areas over the previous iterations, it does not significantly shorten the whole EIA process illustrated in Fig. 7. nor does it eliminate in and of itself the uncertainties created by the complex screening process or the many national legal divergences between member states (Ciobanu-Dordea, 2014; CC, 2014). Henceforth, additional reforms would be required to enhance the Directive in terms of legal certainty, efficiency and cohesion, elements that were already attempted with the current version.

Moreover, developers remain cautious about the increase of public participation and the more stringent criteria with regards to the quality of the environmental reports and screening opinions. The Directive requires developers and EIA review authorities to make all information accessible online besides the stipulation that competent experts must prepare and review the reports. This leads to concerns over rising overall EIA-associated costs and procedural delays, if either the developers or the competent authorities do not have the means or the personal resources to assure this elevated quality degree for environmental reports or screening opinions (CC, 2014; Lownes, 2016). Moreover, the factors of cost and performance have become especially relevant in light of the Directive's expanded the EIA scope, outlining additional Annex III criteria for consideration including climate change, GHG emissions, biodiversity and risks from natural or man-made disasters, thus increasing the overall complexity and need for expert knowledge and survey study resources.

The requirement for a public consultation period of minimum 30 days is also an element of controversy as it prolongs the process additionally, and regions where the duration was formerly shorter, for example the federal Walloon region in Belgium with a public consultation period of previously 15 days, need to revise this time-frame in their legal frameworks (Stibbe, 2014). Furthermore there remains considerable doubt on whether extended public consideration will even have an impact, given the fact that most people, with regards to large-scale onshore wind power developments, have already made up their minds about wind farms at the beginning of the public consultation stage and seldom change their views afterwards, regardless of the degree of public participation or stakeholder involvement (Smart et al., 2014).
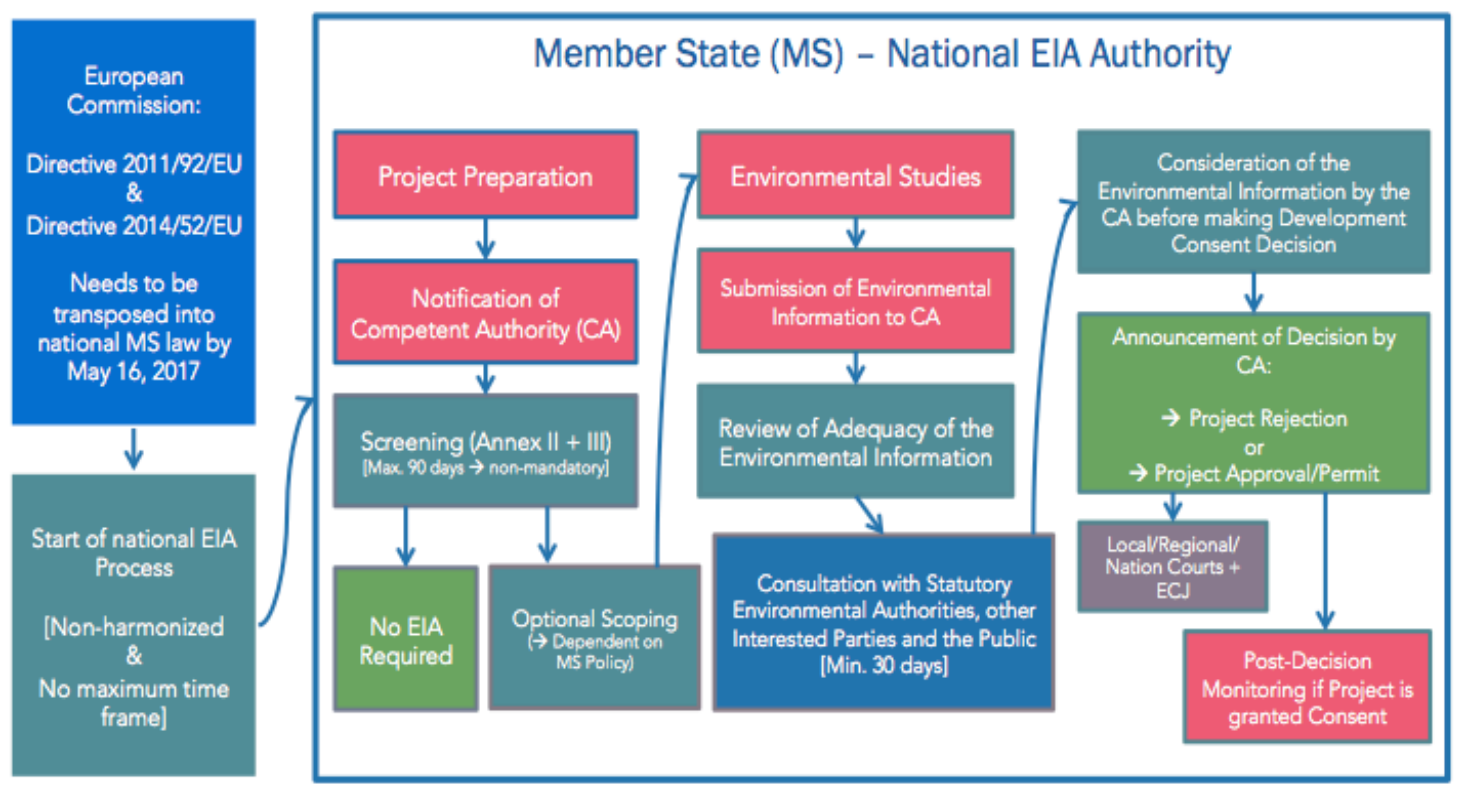

Fig. 7. Basic EIA procedural steps for LS-RE projects (Source: adapted from 2014/52/EU) 
Another perceived flaw of the Directive is that it did not create a unified "one-stop-shop" obligation for member states in order to coordinate the EIA procedure with the general permitting process. This leads to a situation where large-scale wind power projects often become subject to several environmental assessments prescribed in separate directives (e.g. "Habitats Directive 1992", "Bird Directive 2009", "Industrial Emissions Directive 2010", "Water Framework Directive 2000" and "SEA Directive 2011") performed by several authorities. This can lead to increased administrative backtracking as well as procedural replications or repetitions, and thus put projects at risk of running into considerable cost and duration overrun throughout the entire permitting process, especially in case of transboundary or interregional projects (Ciobanu-Dordea, 2014; CC, 2014; Lownes, 2016).

In the light of these criticisms acknowledged by the European Commission (EC), the next section will focus on several post-Directive efforts that were implemented in order to mitigate the negative impact of unaddressed procedural shortcomings, inconsistencies and uncertainties. In addition, several pre-Directive EU policy initiatives might also serve as a roadmap to reduce for example the current average overall administrative lead time of 42 months for obtaining a development consent for large-scale wind power projects, as well as minimize the elevated EIA process cost (EU-27 average: €41000) and general duration differences between member states (Cena et al., 2010).

\subsection{Environmental Approval Procedural Reform Efforts}

Even though the Directive was meant as a substantial measure of streamlining the whole EIA process in order to reduce the administrative barriers therein and facilitate the whole procedure for potential developers, the EC outlined some fundamental flaws of the amended EIA legal framework. As detailed by several EC policymakers in charge of the original Directive reform draft, many provisions got progressively diluted over the course of the internal negotiation stages by either the European Parliament (EP) or the European Council (hereafter the Council) (Ciobanu-Dordea, 2014). Most of the opposition emanated from the Council, the EU representative body of the member states, especially towards mandatory scoping, one-stop-shops and binding time-frames. One of the main reasons appears to be the fear of most states that it would burden existing agencies in charge of the EIA process too much, and would not allow for enough flexibility. Furthermore, some states would have had to reform their administrative organizational competence allocations profoundly in order to set up one-stop-shops, which was therefore rejected by several member states with complex bureaucracies (Ciobanu-Dordea, 2014).

Some other significant provisions in the original Directive draft by the EC were not retained in the final version adopted by the EP and the Council, for example obligatory scoping, which now only needs to be provided upon request by the developer. However, the most notable unmet efficiency objective revolved around the specific obligatory time-frames for decisionmaking, that "the Commission proposed in order to increase legal certainty and accelerate the process of adopting the screening and EIA decisions" (Ciobanu-Dordea, 2014).

Apart from the minimum time-frame of 30 days for public consultation, all other proposed obligatory time-frames, for example 45 days for screening and 60 days for the final decision (after all required documents outlined at the scoping stage had been received), were either extended and rendered non-binding (screening should take max. 90 days) or, in case of a final overall mandatory decision time-frame, not retained altogether (Ciobanu-Dordea, 2014).

To offset these administrative shortcomings, the EC has started to issue certain guidance documents in order to increase the coherence between national member state EIA legal 
frameworks and promote a more uniform application of EU law. Furthermore, these guidance documents also intend to shorten the whole EIA process without having any legally binding force and thus possess only consultative character to member states. The first guidance document covers the project categories in Annexes I and II to provide clarity of what attributes and aspects need to be considered when determining whether or not a project belongs to one these categories and will be subject to the EIA procedure (EC, 2015c).

Another guidance document provides details how member states can set up "one-stop-shops" and "coordinated and joint procedures" for the various project assessments contained in the numerous environmental directives (e.g. "Habitats Directive", "Bird Directive", "Integrated Pollution Prevention and Control Directive" (IPPC), "Industrial Emissions Directive" (IED), "Water Framework Directive" (WFD) and "SEA Directive") (Guidance 2016/C 273/0). This will lead to a more efficient use of national review authority resources, which in combination with the overall streamlining of environmental assessment procedures, can lead to potentially significant EIA process duration reductions.

These guidance documents draw additional inspiration from EU Regulation No 347/2013, also known as "TEN-E Regulation" (hereafter the Regulation), that was introduced by the EU in 2013, and considering the fact that for regulations the principle of subsidiarity does not apply, this represents a binding legislative act that mandates immediate and obligatory member state implementation (Van Zeben, 2014).

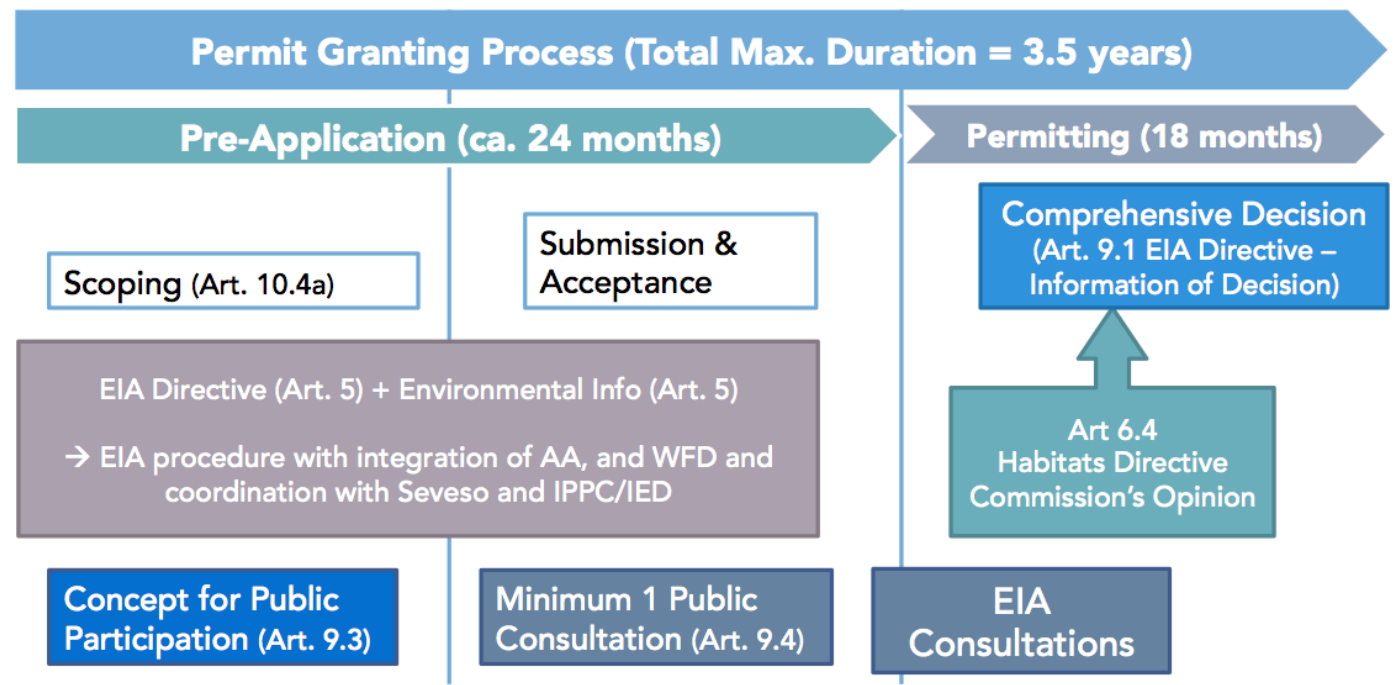

Fig. 8. TEN-E Procedure for "PCI" Projects (Source: adapted from Regulation 347/2013)

The Regulation sets out a comprehensive legal and policy framework to optimize electricity network development within the EU and creates a category of "Projects of Common Interest" (PCI) that will benefit from a preferential regulatory treatment that contains streamlined permitting procedures such as appropriate assessment (AA) and financial incentives.

The regulatory framework under this regulation implements administrative facilitations and streamlining measures that are extremely beneficial for developers, as the latter can benefit from accelerated planning and permit granting procedures including a binding three-and-ahalf-years time limit for the granting of a permit as can been seen in Fig. 14., with minor extensions allowed only under special circumstances (Regulation (EU) No 347/2013; EC, 2013). This leads to lower administrative costs for project promoters and authorities resulting from the streamlining of their environmental assessment procedures. And finally, there is a one-stop shop obligation for member sates in that each one of them has to designate or create competent national authority for coordinating or examining all documentation. 
However, the largest drawback in terms of RE development is that momentarily only transboundary energy infrastructure projects such as transmission lines or electricity storage facilities are listed among the energy-related PCI categories and henceforth fall within the scope of this preferential framework, energy generation including RE power plants do not qualify for this preferential scheme yet.

\section{Results}

Table 3

Results of Procedural Framework Comparison for LS-RE projects (MOEJ, 2012a; Uesako, 2013; METI, 2016a; Directive 2014/52/EU; Cena et al., 2015)

\begin{tabular}{lll}
\hline EIA Procedure & Japan & EU \\
\hline Pre-EIA & Yes & National Variations \\
Screening & Yes & Yes \\
Scoping & Yes & Yes (Non mandatory - National \\
& & Variations) \\
Expert-validated Assessment & No (In theory, in practice & Yes \\
& MOEJ/METI reviews amount to & \\
Public Participation Mandatory & expert assessment) & Yes \\
& Yes & (30 days min.) \\
Post-Monitoring & (45 days +45 days & Yes \\
Overall Average Duration & $=90$ days total) & ca. 42 months (EU-27) \\
Average Procedural Steps & Yes & 18 (EU-27) \\
\hline
\end{tabular}

Looking at the individual procedural components in Table 3 of the Japanese and EU EIA legal frameworks and the respective reform efforts, it becomes apparent, that although EIA is only one of many factors acting as a barrier to large-scale RE development, the environmental approval process certainly contributes the to high costs and overall length of the permitting procedures mandatory for RE project developers. However, streamlining and procedural reforms can trigger notable outcomes. In Japan, a combination of the aforementioned recent EIA procedural modifications, which still remain largely in test stages, shows preliminary results that point to a $667 \%$ increase in EIA applications for wind farms between 2013 and 2015, as can been observed in Fig. 9. This sector previously displayed only stagnant growth rates between 2011, when wind power projects became subject to EIA under the amended law, and 2013, when some of the first reform measures were launched (METI, 2015).

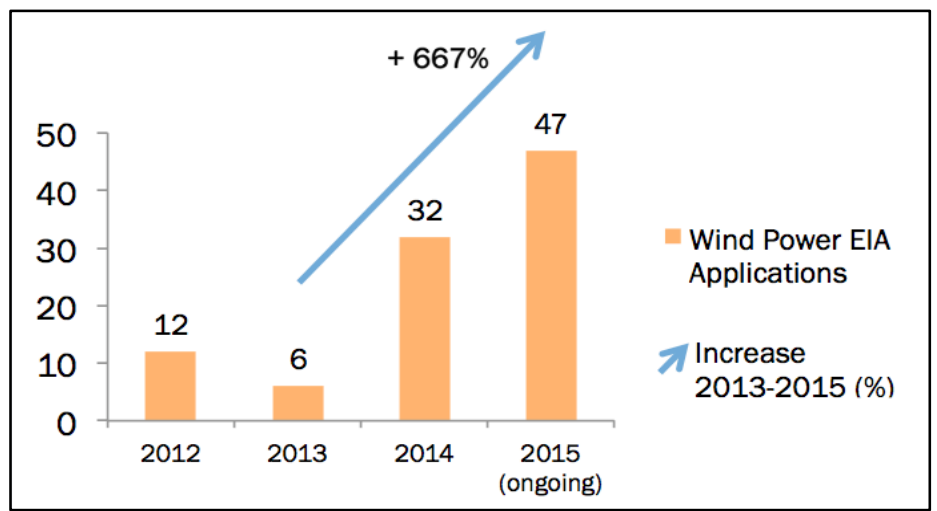

Fig. 9. Wind Power EIA Applications from 2012 to 2015 (ongoing) (Source: METI, 2015) 
The impact of the new EIA Directive still remains to be seen, as all of the observed member states have not yet fully implemented the Directive's provisions. However looking at early assessments and the results of the semi-structured EIA expert interviews, it seems that the impact will be quite limited as most states have been opting only for soft implementations, meaning that they will use the least integrated and least stringent regulatory thresholds allowed by the Directive (Clement, 2014; EUFJE, 2014; Philipp and Sangenstedt, 2014; Stibbe, 2014). This will do only little to overcome some of the complications of the current framework, thereby underlining the obstructive potential of EIA, cited in the broad and extensive "Wind Barriers" study as the most frequent and serious administrative barrier to LS-RE, especially wind power, in the EU (Cena et al., 2010).

Among the interviewed Japanese experts, a large heterogeneity was observed with regards to the influence of EIA procedures on LS-RE development. Experts JP14 and JP15 for example pointed out that although Japanese RE industry organizations do identify EIA as a problem that could be solved through streamlining, they consider financial, such as the FiT, and electricity market regulation factors as the more crucial variables influencing RE growth.

Another important point that expert JP2 addressed was the division of competences between the different ministries that complicates numerous EIA applications with regards to LS-RE projects. He sees no possibility for a comprehensive, integrated one-stop-shop option in the near future. As already illustrated in Fig.3., METI and MOEJ both provide advisory opinions throughout the various stages of the EIA process for energy projects, however the ultimate and final decision-making competences for power generation projects reside with METI, thus, energy policy considerations or motivations can override ecological and socio-environmental concerns. Hence, streamlining efforts that would further reduce environmental standards and civil society inlets might not be in the best interest of overall conservation efforts. This contentious aspect is also raised by expert JP3, who feels that given the anti-environment agenda of the current administration, lowering environmental standards to promote LS-RE should not be envisioned since it could put local ecosystems into peril, especially since national EIA reviews for LS-RE projects do constitute only a small fraction of the overall number of environmental assessments, amounting to roughly 20 per year.

Experts JP12 and JP13 consider the current Japanese EIA system fairly balanced and not too much of a burden to developers. After the Fukushima Daiichi nuclear disaster, having additional procedural steps, such the SEA-like PEIC, while enabling developers and locals to communicate on multiple occasions is seen as an advantage in reducing ulterior conflicts, position that is confirmed by experts JP6 and JP7, active in LS-RE project development. They argue that even before the 2011 EIAL amendment, which subjected large-scale wind power projects to mandatory EIAs, many wind power projects were already abandoned due to strong local resistance or preferential development prospects for solar PV or biomass. Therefore the EIAL's influence on project outcomes appears to be limited. They also mention that in the future, mega solar PV plants might also be included in the EIAL due to their large land use footprint. However they do acknowledge, that further improvement of the EIAL could lead to increased LS-RE project developments.

These sentiments were mostly echoed by the European experts EU3 and EU4, who do confirm that many member states did see the sense in the newly amended Directive 2014/52/EU seen as an improvement, although the Directive's overall significance is downplayed. This can be explained by considering that the number of actually implemented modifications, as opposed to the ones that are merely optional, remains limited, and thus many member states need institute only minor changes to their existing EIA frameworks. Moreover, a high number of member states did not want to reorganize their existing review structures and thus argued in a favor of a Directive that mandates that only few articles require transposition. 
The current national transpositions of the previous EIA directives illustrated by Clement, (2014), EUFJE (2014), Philipp and Sangenstedt (2014) as well as Stibbe (2014), do show a heterogeneous situation in terms of transboundary procedural uniformity. Almost all states do divide the EIA review process among several government agencies to varying degrees of coordination, which perform the multitude of various procedures required by several directives such as the Directive 2008/1/EC (IPPC), 92/43/CEE (Habitats) and 2009/147/CE (Birds), at times within an integrated procedural framework, at times disjointed and split up among numerous government bodies and regulations.

Therefore, the three main objectives of the revision of the EIA Directive, strengthening the quality of the assessments, improving the overall coherence and synergies with other EU legislation and simplifying procedures, were only achieved to a limited degree. Experts EU1, EU2, EU3 and EU4, are uniform in their opinion that member states missed a unique opportunity to create a more comprehensive and accessible framework and thus further improvements are required. Looking at the ardent opposition from civil society to certain LSRE projects, it becomes apparent that the EU EIA review process needs to find the right balance between the EU climate change commitments and localized civil society concerns as legal challenges in Ireland and Bulgaria have shown, that mainly revolved around the omission of or insufficient environmental studies within the context of EIA reviews for largescale wind farm projects (RTE, 2016; SG, 2016).

\section{Discussion and Conclusion}

Given the RE generation targets set by Japan (22-24\% share of TPES until 2030) and the EU (27\% share of RE consumption until 2030), combined with their planned GHG emission reductions ( $26 \%$ in Japan by 2030 , baseline 2013 ; and $40 \%$ in the EU by 2030 , baseline 1990 ), large-scale $\mathrm{RE}$ is a domain that requires further development if these targets are to be achieved (Urakami, 2015; EC, 2015a, 2015b). Japan's current reform efforts remain mostly limited to certain policy areas and remedy only specific scenarios without tackling the general structural complexity resulting from numerous administrative barriers, contained in the various environmental laws establishing the permitting processes, in a comprehensive and holistic manner.

However with regards to potential EIA law reform blueprints, the newly amended EU EIA Directive offers only little improvements over the old versions and does not include mandatory one-stop-shops or specific time-frames for decision-making. Henceforth, the most comprehensive source of inspiration for Japan would be less the Directive but rather the "TEN-E" Regulation of 2013, which implements these administrative elements into a sectorand purpose-specific EIA process and makes them binding for energy infrastructure projects categorized as PCI.

Looking at these TEN-E provisions could help reform the Japanese EIA process through the establishment of a one-stop-shop approach in addition to increased coordination regarding the various permitting procedures by both local governments and the national government. In combination with specific maximum time-frames, this could render the whole process more cost-efficient, provide more clarity and legal certainty for developers, authorities and the public, and shorten the overall duration of the whole process. Furthermore, creating a specific Japanese priority category counterpart for LS-RE projects similar to the EU PCIs could earmark the streamline EIA process for only a pre-determined group of projects and reduce administrative burden for a potential future one-stop-shop review authority.

For both the Japanese government and the EU, low electricity prices, grid stability and energy security generally take priority over other considerations such as environmental or climate change concerns. Whereas the EU has made efforts to diversify its energy portfolio in the 
post-Paris Agreement era, recent developments in Japan are still encumbered by regulatory shortcomings of the electricity market that continues to be dominated by the main ten regional electric utilities that have been enjoying quasi-monopolies in their geographically delimitated service areas.

Recently, these utilities started to limit their input capacities for RE generated electricity, citing grid stability issues, thus leaving many potential RE developers without the possibility to sell their production output.

Therefore further research would entail a closer look at the previous role of the electricity market and how these proposed reform efforts would affect overall RE deployment as well as how grid connection and market access barriers can progressively be reduced, so that the increased RE production capacities resulting from a streamlined EIA procedure can effectively be integrated into the electricity grid.

\section{Acknowledgements}

The author would like to extend his thanks to the various interviewees for their time. He also would like to thank the Institute of Energy Economics, Japan (IEEJ), which provided material and logistic support throughout the writing process of this paper. He acknowledges the financial support for his studies provided by the Japanese Government through the MEXT $\mathrm{Ph} . \mathrm{D}$. scholarship program. Finally, he would also like to express his appreciation for the contributions of his fellow colleagues of the University of Tokyo GPES program, providing valuable input and constructive feedback during the development of this paper.

\section{References}

Azechi, K., Nishikizawa, S. and Harashina, S., 2012, EIA as a Conflict Mitigation Tool for Wind Farm Projects in Japan, Proceedings of the $32^{\text {nd }}$ Annual Conference of IAIA, 27 May-1 June 2012, Porto, Portugal

Bryman, A., 2008. Social Research Methods. Oxford University Press, New York

Ciobanu-Dordea, A., European Commission (EC), 2014, Revision of EIA Directive, Retrieved from http://www.eufje.org/images/docConf/bud2014/pres11\%20bud2014.pdf (last accessed August 14, 2016)

Cena, A., Iuga, D., Simonot, E., Fichaux, N., Wokke, S. and Strom, S., European Wind Energy Association (EWEA), 2015, WindBarriers: Administrative and grid access barriers to wind power, Retrieved from http://www.windbarriers.eu/fileadmin/WB_docs/documents/WindBarriers_report.pdf (last accessed August 20, 2016)

Clement, M., EU Forum of Judges for the Environment (EUFJE), 2014, Report on France: Impact Assessments - Preventive Measures against Significant Environmental Impacts in the 21st Century, Retrieved from http://eufje.org/images/docConf/bud2014/FR\%20bud2014.pdf (last accessed August 24, 2016)

CC (Clifford Chance), 2014, Briefing note: Watered-Down Revisions to EU Environmental Impact Assessment rules finalised, Retrieved from http://www.cliffordchance.com/content/ dam/cliffordchance/PDFs/WateredDownRevisionsEUEIAMay\%202014.pdf (last accessed June 22, 2015)

Demizu, S., Standard Examiner, 2016, Japan steps up efforts to protect birds from wind turbines, Retrieved from http://www.standard.net/World/2016/09/18/Japan-steps-up-efforts-to-protect-birdsfrom-wind-turbines.html (last accessed August 7, 2016) 
Directive 2014/52/EU of the European Parliament and of the Council of 16 April 2014 amending Directive 2011/92/EU on the assessment of the effects of certain public and private projects on the environment

EC (European Commission), 2009, Report from the Commission to the Council, the European Parliament, the European Economic and Social Committee and the Committee of the Regions: On the application and effectiveness of the EIA Directive (Directive 85/337/EEC, as amended by Directives 97/11/EC and 2003/35/EC), Available at (http://eur-lex.europa.eu/legal-content/ EN/TXT/PDF/?uri=CELEX:52009DC0378\&from=EN) (last accessed July 6, 2016)

EC, 2011, Permit granting procedures for energy infrastructure projects, European Commission, Brussels, Belgium, Retrieved from, Retrieved from https:/ec.europa.eu/energy/sites/ener/files/documents/20110430_infrastructure_summary.pdf (last accessed August 24, 2016)

EC, 2012, Proposal for a Directive of the European Parliament and the Council amending Directive 2011/92/EU on the assessment of the effects of certain public and private projects of the environment, Retrieved from http://eur-lex.europa.eu/legal-content/EN/TXT/ PDF/?uri=CELEX:52012PC0628\&from=EN (last accessed July 6, 2016)

EC, 2013, Streamlining environmental assessment procedures for energy infrastructure Projects of Common Interest (PCIs), Retrieved from http://ec.europa.eu/environment/eia/pdf/PCI_guidance.pdf (last accessed July 6, 2016)

EC, 2015a, Environment Council approves the EU's intended nationally determined contribution to the new global climate agreement, European Commission, Brussels, Belgium, Retrieved from http://ec.europa.eu/clima/news/articles/news_2015030601_en (last accessed August 7, 2016)

EC, 2015b, Europe's renewable energy success on show at COP21, European Commission, Brussels, Belgium, Retrieved from https://ec.europa.eu/energy/en/news/europes-renewable-energy-successshow-cop21 (last accessed August 7, 2016)

EC, 2015c, Interpretation of definitions of projects categories of annex I and II of the EIA Directive, Retrieved from http://ec.europa.eu/environment/eia/pdf/cover_2015.pdf (last accessed July 6, 2016)

EUFJE (EU Forum of Judges for the Environment), 2014, Report on the United Kingdom: Impact Assessments - Preventive Measures against Significant Environmental Impacts in the 21st Century, Retrieved from http://eufje.org/images/docConf/bud2014/UK\%20bud2014.pdf (last accessed August 24, 2016)

Haarscher, A., Bruner, M., Doblas, J., Fargere, A., Ashley, S.F. and Nuttall, William, 2014, The Japanese Electricity System 15 months After March 11th 2011, Cambridge Working Papers in Economics 1443, Retrieved from http://www.econ.cam.ac.uk/research/repec/cam/pdf/CWPE1443.pdf) (last accessed July 10, 2016)

Galás, S., Galás, A., Zelenáková, M., Zvijáková, L., Fialová, K. and Kubícková, H., 2015, Environmental Impact Assessment in the Visegrad Group countries, Environmental Impact Assessment Review 55, 11-20

Geißler, G., Köppel, J. and Gunther, P., 2013, Wind energy and environmental assessments - A hard look at forerunners' approaches: Germany and the United States, Renewable Energy 51, 71-78

Guidance 2016/C 273/0 - Commission guidance document on streamlining environmental assessments conducted under Article 2(3) of the Environmental Impact Assessment Directive (Directive 2011/92/EU of the European Parliament and of the Council, as amended by Directive 2014/52/EU)

IEA (International Energy Agency), 2015, Renewables Information 2015, OECD/IEA, Paris, France. 
Ito, T., Ministry of Environment, Japan (MOEJ), 2014, Current Situation for EIA in Japan, Available at (http://www.aecen.org/sites/default/files/

5_overview_of_the_eia_implementation_in_japan_.pdf) (last accessed January 4, 2016)

JFS (Japan for Sustainability), 2016a, Japan's Environment Ministry Announces Proposals for Reducing GHG Emissions, from http://www.japanfs.org/en/news/archives/news_id035628.html (last accessed August 7, 2016)

JFS, 2014a, Hot Springs Power Generation to Start at Disaster Evacuation Facility in Japanese Resort Town, Retrieved from http://www.japanfs.org/en/news/archives/ news_id035012.html (last accessed June 24, 2016)

JFS, 2013, Renewable Energy in Japan - Current Trends Show Promise and Opportunities, Retrieved from http://www.japanfs.org/en/news/archives/news_id034505.html (last accessed June 24, 2016)

JFS, 2014b, Japanese Ministry Decides to Support Three Geothermal Projects, Retrieved from http://www.japanfs.org/en/news/archives/news_id034707.html (last accessed June 24, 2016)

JFS, 2014d, New Renewable Energy Law to Allow Conversion of Farmland in Japan to Wind Farms, Retrieved from http://www.japanfs.org/en/news/archives/news_id034849.html (last accessed August 5, 2016)

Johnston, E. and Yoshida, R., The Japan Times, 2015, In major victory for nuclear industry, first reactor goes online under post-Fukushima regime, Retrieved from http:/www.japantimes.co.jp/news/2015/08/11/national/kagoshima-reactor-restarted-first-go-onlinepost-fukushima-regime/\#.VcnVzbePJ4t) (last accessed August 11, 2016)

Jones, C.R., Orr, B.J. and Eiser, R., 2011, When is enough, enough? Identifying predictors of capacity estimates for onshore wind-power development in a region of the UK, Energy Policy 39, 4563-4577

JT (The Japan Times), 2015, Japan, South Korea stick to coal plant policies despite global climate deal, Retrieved from http://www.japantimes.co.jp/news/2015/12/16/national/science-health/japan-southkorea-stick-coal-plant-policies-despite-global-climate-deal/\#.WEI8X5KfPXs (last accessed August 24, 2016)

Katori, K., The Asahi Shimbun, 2015, Ministry to allow drilling in national parks to gain geothermal power, Retrieved from http://ajw.asahi.com/article/behind_news/social_affairs/AJ201507310037 (last accessed August 11, 2015)

Kotsubo, Y. and Takeuchi, K., 2013, Japan's feed-in-tariff system for clean energy mired in regulations, Retrieved from http://ajw.asahi.com/article/sci_tech/environment/AJ201305220009 (last accessed July 27, 2016)

Lownes, V., Deloitte, 2016, Transposing the amended EIA Directive - preparing for change, Retrieved from http://blogs.deloitte.co.uk/realestate/2016/02/transposing-the-amended-eiadirective.html?utm_source=Mondaq\&utm_medium=syndication\&utm_campaign=View-Original (last accessed August 24, 2016)

METI (Ministry of Economy, Trade and Industry, Japan), 2015, Long-term Energy Supply and Demand Outlook Subcommittee Report: Power Generation Cost Evaluation [Translated from Japanese Original], Retrieved from http://www.enecho.meti.go.jp/committee/council/basic_policy_subcommittee/mitoshi/cost_wg/007/pdf /007_05.pdf (last accessed August 24, 2016)

METI, 2016a, White Paper on Energy 2016: Chapter 3 - Transformation of Energy Policy Based on the Paris Agreement: Section 2 - Energy policy to realize balance between environmental constraints and growth $\sim$ Energy innovation strategy $\sim$ [Translated from Japanese Original], Retrieved from http://www.enecho.meti.go.jp/about/whitepaper/2016html/1-3-2.html (last accessed August 29, 2016) 
METI, 2016b, The Sites selection Project for Wind Power Plants initiated by regional communities Retrieved from http://www.env.go.jp/policy/assess/7-1asiaeia2016_pdf/asiaeiaconference2016-g7.pdf (last accessed August 30, 2016)

MOEJ (Ministry of Environment Japan), 2012a, Environmental Impact Assessment in Japan, Retrieved from http://www.env.go.jp/policy/assess/1-3outline/img/pamph_e.pdf (last accessed July 14, 2016)

MOEJ, 2013, Shortening the Assessment Process for Thermal Power Plant Replacements [Translated from Japanese Original], Retrieved from http:/www.env.go.jp/policy/assess/57expedite/no121130301b.pdf (last accessed August 24, 2016)

MOEJ, 2015, National Park Systems: Park Plans, Retrieved from http://www.env.go.jp/en/nature/nps/park/system/keikaku.html (last accessed August 11, 2016)

MOEJ, 2012b, Towards a Smooth Implementation of Environmental Assessment for Wind Power Generation Projects [Translated from Japanese Original], Retrieved from http://www.env.go.jp/policy/assess/4-7windpower/jigyo.pdf (last accessed August 23, 2016)

Nishikizawa, S., Mitani, T. and Murayama, T., 2013, Perception and Annoyance Related to Environmental Impacts of Coastal Wind Farms in Japan, Proceedings of the $33^{\text {rd }}$ Annual Conference of IAIA, 13-16 May 2013, Calgary, Canada

Philipp, R. and Sangenstedt, C., EU Forum of Judges for the Environment (EUFJE), 2014, Report on Germany: Impact Assessments - Preventive Measures against Significant Environmental Impacts in the 21st Century, Retrieved from http://eufje.org/images/docConf/bud2014/DE\%20bud2014.pdf (last accessed August 24, 2016)

Regulation (EU) No 347/2013 of the European Parliament and of the Council of 17 April 2013 on guidelines for trans-European energy infrastructure and repealing Decision No 1364/2006/EC and amending Regulations (EC) No 713/2009, (EC) No 714/2009 and (EC) No 715/2009 Text with EEA relevance

RTE, 2016, Court hears challenge to Tipperary wind farm plan, Retrieved from http://www.rte.ie/news/ireland/2016/0303/772407-tipperary-wind-farm/ (last accessed August 24, 2016)

Schumacher, K., 2015, Comparative Analysis of the Environmental Impact Assessment Procedures of Japan and New Zealand, The International Journal of Sustainability Policy and Practice 11(2), 11-21

Shibata, Y., Tsukimura, Y. and Takemae, Y., 2015, SEA approaches for Geothermal Development in Japan and New Zealand: Comparison of Development Process, Proceedings of the $35^{\text {th }}$ Annual Conference of IAIA, 20-23 April 2015, Florence, Italy

Smart, D.E., Stojanovic, T.A. and Warren, C.R., 2014, Is EIA part of the wind power planning problem?, Environmental Impact Assessment Review 49, 13-23

SG (The Sofia Globe), 2016, European Court of Justice finds against Bulgaria in Kaliakra conservation case, Retrieved from http://sofiaglobe.com/2016/01/14/european-court-of-justice-finds-againstbulgaria-in-kaliakra-conservation-case/ (last accessed August 24, 2016)

Stibbe (2014), Revised European Directive on Environmental Impact Assessment ('EIA') for projects, Retrieved from http:/www.stibbe.com/en/news/2014/may/bru-project-mer-uk (last accessed August 24, 2016)

TU Berlin, 2011, German legislation and planning process for solar and wind energy, Retrieved from http://lehre.umweltpruefung.tu-berlin.de/wiki_mw/doku.php?id=german_legislation_and_planning_ process_for_solar_and_wind_energy 
Ueasako, D., Kamita, K. and Uesugi, T., 2013, Streamlined EIA Procedures for Power Plant Replacement in Japan, Proceedings of the $33^{\text {rd }}$ Annual Conference of IAIA, 13-16 May 2013, Calgary, Canada

Uesako, D., Ministry of Environment, Japan (MOEJ), 2013, Streamlined EIA Procedures for Power Plant Replacement, Retrieved from https:/www.env.go.jp/en/focus/docs/files/20130513-75.pdf (last accessed August 24, 2016)

Urakami, A., MOEJ, 2015, Japan's INDC and current climate change policies, Retrieved to http://www.env.go.jp/earth/ondanka/attach_8/2_1_Akiko_s_INDC_and_climate_change_policies_092 9_2015_fin.pdf (last accessed August 6, 2016)

Van Zeben, J., 2014, Subsidiarity in European Environmental Law: A Competence Allocation Approach, Harvard Environmental Law Review 38(2), 415-464

Watanabe, C. and Stapczynski, S., The Japan Times, 2016, Sun no longer shines on Japan's solar boom as subsidies wane, Retrieved from http://www.japantimes.co.jp/news/2016/07/14/national/sun-nolonger-shines-japans-solar-boom-subsidies-wane/\#.WEI8bZKfPXs (last accessed August 24, 2016) 